\title{
Modified Palmer Drought Severity Index Based on Distributed Hydrological Simulation
}

\author{
Denghua Yan, ${ }^{1}$ Xiaoliang Shi, ${ }^{1,2}$ Zhiyong Yang, ${ }^{1}$ Ying Li, ${ }^{2}$ Kai Zhao, ${ }^{2}$ and Yong Yuan ${ }^{1,3}$ \\ ${ }^{1}$ Department of Water Resources, State Key Laboratory of Simulation and Regulation of Water Cycle in River Basin, \\ China Institute of Water Resources and Hydropower Research, Beijing 100038, China \\ ${ }^{2}$ Northeast Institute of Geography and Agroecology, Chinese Academy of Sciences, Changchun 130102, China \\ ${ }^{3}$ College of Soil and Water Conservation, Beijing Forestry University, Beijing 100083, China
}

Correspondence should be addressed to Xiaoliang Shi; shixiaoliang0305@gmail.com

Received 5 February 2013; Accepted 27 May 2013

Academic Editor: Yongping Li

Copyright (C) 2013 Denghua Yan et al. This is an open access article distributed under the Creative Commons Attribution License, which permits unrestricted use, distribution, and reproduction in any medium, provided the original work is properly cited.

Drought monitoring at large scale is essential for fighting against drought. Aiming at the limitation of acquiring long-time serial soil moisture and actual evapotranspiration for Palmer drought severity index (PDSI), the paper modified the PDSI based on distributed hydrological model on subbasin level in Luanhe river basin, North China. The water balance was simulated using the Soil and Water Assessment Tool (SWAT). Calibration and validation results showed good agreement between simulated and measured discharges, and the SWAT model can be used to predict hydrological processes in the study area. Then the simulation results of main hydrologic components were used to establish PDSI. The verification of the drought indices showed that the modified PDSI based on SWAT model and Palmer drought severity index could better describe the characteristics of regional drought evolution in the Luanhe river basin. High drought frequency areas were mainly distributed in the grassland regions of upstream located in the eastern part of Inner Mongolia plateau, and the drought area had a significant upward trend form 1973 to 2010. Compared with the traditional Palmer drought severity index, the modified PDSI could reflect the spatial heterogeneity of regional drought and improve the physical mechanism of PDSI. The drought monitoring method can provide technical support for comprehensive understanding of drought and effective preventing and relieving of drought disasters.

\section{Introduction}

Drought is a major natural hazard that can have devastating impacts on regional agriculture, water resources, and the environment, with farreaching impacts in an increasingly globalized world [1]. Besides, droughts are the world's costliest natural disasters, causing an average $\$ 6-\$ 8$ billion in global damages annually and affecting more people than any other form of natural disasters [2].

It is important to assess and monitor drought due to the consequences and pervasiveness of drought, and various drought indices had been derived to encapsulate drought severity on a regional basis and provide information for decision maker in recent decades [3]. Based on the considerable disagreement that exists about the definition of drought, the drought indices can be sorted as precipitation indices, soil moisture indices, water budget indices, and hydrological and various aridity indices [4]. The commonly used drought indices include standardized precipitation index (SPI) [5], Palmer drought severity index (PDSI) [6], and surface water supply index (SWSI), vegetation condition index $[7,8]$. Heim [9] gave a comprehensive review of 20th century drought indices used in the United States.

Palmer Drought Severity Index (PDSI) is perhaps the most widely used regional drought index for monitoring droughts [10-12]. PDSI was developed by Palmer [13] to simulate moisture content of the soil month by month and to compare its monthly anomalies at regions having different climate and seasons [4]. Although referred to as an index of meteorological drought, the PDSI is based on meteorological and soil moisture content, it takes into account precipitation, evapotranspiration, and soil moisture conditions [10], and the PDSI can be used to determine the beginning, ending, and severity of the drought period; it has been normalized so as 
to allow comparisons across space and time. However, the PDSI is traditionally calculated by using a two-layer buckettype model to obtain data on water balance components. This model does not consider the effects of factors such as the spatial heterogeneity of soil, vegetation cover, and topography on watershed hydrological processes. Moreover, in present relative researches, the calculation of PDSI was mainly based on the records of meteorological stations at point scale, have the limitation of acquiring long-time serial soil moisture and actual evapotranspiration at large scale, and cannot clearly reflect the regional difference of drought. Besides, the PDSI uses a simplified model of potential evaporation that responds only to changes in temperature and thus responds incorrectly to global warming in recent decades [14].

Distribution hydrological model is increasingly being used to simulate hydrological processes involved in hydrological cycle [15]. These models can provide some key hydrologic components of long-time serial and large spatial extent (soil moisture, evapotranspiration, surface runoff, etc.) for the calculation of PDSI. As such, the accuracy of PDSI value could potentially be improved by using distribution hydrological model rather than the traditional two-layer bucket-type model for hydrological accounting.

For better reflecting the spatial heterogeneity of regional drought, the feasibility that integrates the distribution hydrological model and PDSI for monitoring drought at large scale was verified. To achieve this, the paper calibrated and validated the Soil and Water Assessment Tool (SWAT) in the Luanhe river basin located in North China, where there is a drought-prone area. Then the Palmer drought model was modified based on the simulation results of hydrological processes, and the spatial and temporal variation of regional drought was analyzed. The evaluation results based on modified PDSI may provide some scientific support for decision makers when formulating drought management policies to alleviate the adverse effects of drought.

\section{Materials and Methods}

2.1. Study Area. Luanhe river is the second largest river that separately flows into sea in North China. It originates from the northern foot of the Bayanguertu Mountain, near the border between Hebei province and Inner Mongolia autonomous region, and finally flows into Bohai Sea (Figure 1). The total length of the river is about $888 \mathrm{~km}$, and main tributaries have Shandianhe river, Xingzhouhe river, Yixunhe river, Wuliehe river, Laoniuhe river, Liuhe river, Puhe river, Sahe river, and Qinglonghe river.

Luanhe river basin is located in the north-eastern part of North China plain, and has a drainage area of $44,750 \mathrm{~km}^{2}$ with elevations ranging from 2 to $2229 \mathrm{~m}$ (the average elevation is $911 \mathrm{~m}$ ). The basin is characterized by a typical temperate continental climate, with mean annual precipitation ranging from $400 \mathrm{~mm}$ to $700 \mathrm{~mm}$ with $67-76 \%$ falling in June through September, and the mean annual temperature ranges from 5 to $12^{\circ} \mathrm{C}$. The multiannual natural runoff of Luanhe river basin is $46.94 \times 10^{8} \mathrm{~m}^{3}$. The main land use types of the study area are forest (37.76\%), pasture (31.45\%), and

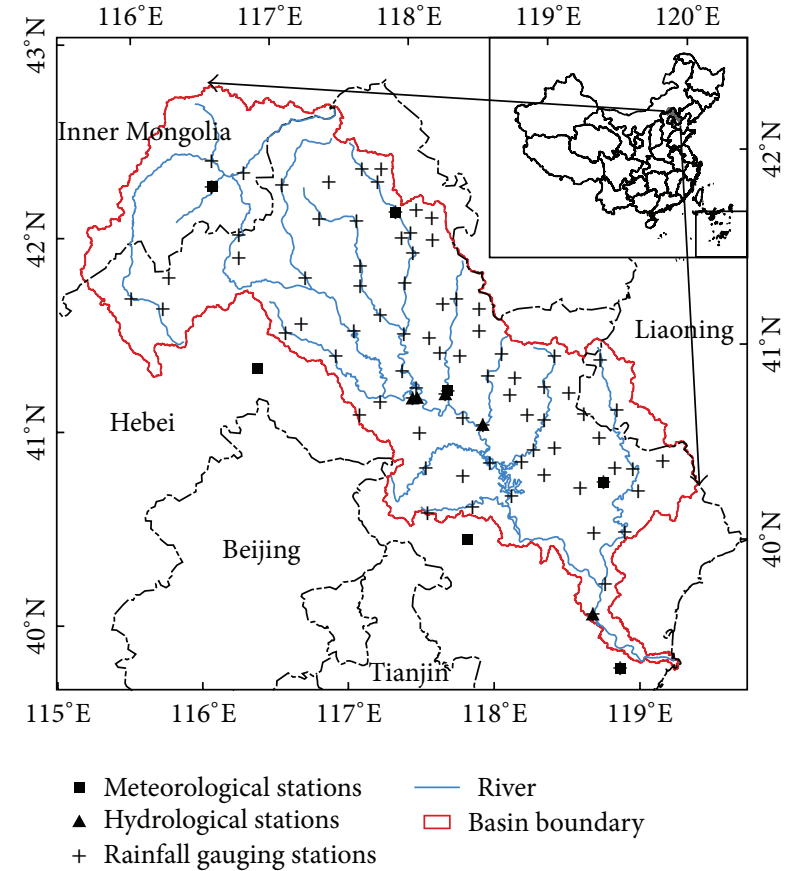

FIGURE 1: Location of Luanhe river basin with hydrological and meteorological stations.

agricultural lands (24.09\%). The predominant soil types of the study area are brown and cinnamon soils.

\subsection{The Establishment of SWAT Model}

2.2.1. SWAT Description. The soil and Water Assessment Tool (SWAT) model is a watershed-scale, physically based, continuous-time, and distributed-parameter hydrological model that operates on a daily time step and is developed to predict the impact of land management practices on hydrologic and water quality response of complex watersheds with varying soils, land use, and management conditions [16]. It has several advantages, such as multiple functions, a modular design, and only a few parameters need to be optimized compared with many other hydrological models [17], so SWAT model was selected in the study.

In SWAT, a watershed is first divided into a number of subbasins according to the terrain and river channels and then further subdivided into multiple hydrologic response units (HRUs) consisting of unique combinations of land use, soils, and topography in each basin. An HRU is a fundamental spatial unit upon which SWAT simulates the water balance [16]. The runoff, sediment, and nutrient loadings from each HRU are calculated separately and then aggregated at the subbasin level and routed to the associated reach and to the basin outlet through the channel network.

The model provides two methods for estimating surface runoff: one is the curve number method developed by the Soil Conservation Service (SCS) of the United States Department of Agriculture and the other is the Green-Ampt method. In most cases, the curve number method is better than the Green-Ampt method [18]. For potential evapotranspiration 
estimation, three methods are available in SWAT, that is, Penman-Monteith, Priestley-Taylor, and Hargreaves methods. Water flow is routed through the channel network using the variable storage method or the Muskingum method [19]. A detailed description of the model can be found form the model's public domain at http://swat.tamu.edu/.

2.2.2. Model Input. The SWAT model requires meteorological data input and three GIS data layers, namely, digital elevation model (DEM), land use, and soil. The SRTM DEM with a spatial resolution of $90 \mathrm{~m}$ was provided by International Scientific Data Service Platform, Computer Network Information Center, and Chinese Academy of Sciences (http:// datamirror.csdb.cn).

Land use map for 1985 and 2000 was obtained from the Data Center for Resources and Environmental Sciences (RESDC), Chinese Academy of Sciences, and land use properties were directly from the SWAT model database.

Soil map at a scale of 1:1000000 was provided by Environmental and Ecological Science Data Center for West China, National Natural Science Foundation of China. (http://westdc.westgis.ac.cn). Soil physical properties (soil particle composition, saturated hydraulic conductivity, and bulk density, etc.) were mainly collected from China soil database (http://www.soil.csdb.cn) and a soil correlation system combined with the soil water characteristics software of SPAW (soil-plant-air-water) [20], which was developed by Washington State University, USA.

SWAT requires daily values of meteorological data as an input. These data are precipitation, maximum and minimum temperature, solar radiation, relative humidity, and wind speed. In the study, daily maximum and minimum air temperature, wind speed, and relative humidity for seven meteorological stations located within and around the watershed during 1970-2010 were collected from the National Meteorological Center of China (Figure 1). The daily solar radiations were estimated with the model based on the sunshine hours and geological information [21]. Due to short time series of daily precipitation records of 83 gauging stations (1972-1988) in the study area, the paper interpolated the daily precipitation of gauging stations with inverse distance weighted method from 1989 to 2010 based on precipitation data of seven meteorological stations.

The monthly natural discharge values were collected from five hydrological stations at the catchment outlet for the period of 1973 to 2000, which used to calibrate and validate the model spatially. The description of these stations and their catchments was list in Table 1.

2.2.3. Model Setup. Luanhe river basin was divided into 174 subbasins and further into 1327 HRUs when 1985 land use map was used and 1471 HRUs when 2000 land use map was used. The SCS curve number method was used for calculating surface runoff volume. The Penman-Monteith method and variable storage method were used to estimate the potential evapotranspiration and flow routing, respectively.

2.2.4. Model Calibration and Validation. Model calibration is an important component of hydrological modeling. In this
TABLE 1: Hydrological stations used for SWAT calibration and validation.

\begin{tabular}{lccc}
\hline $\begin{array}{l}\text { Hydrological } \\
\text { station }\end{array}$ & River & $\begin{array}{c}\text { Catchment area } \\
\left(\mathrm{km}^{2}\right)\end{array}$ & $\begin{array}{c}\text { Area percent } \\
(\%)\end{array}$ \\
\hline Hanjiaying & Yixunhe river & 6736.26 & 14.78 \\
Chengde & Wuliehe river & 2502.21 & 5.49 \\
Xiabancheng & Laoniuhe river & 1679.61 & 3.69 \\
Sandaohezi & Luanhe river & 18560.07 & 40.74 \\
Luanxian & Luanhe river & 44939.82 & 98.63 \\
\hline
\end{tabular}

study, owing to data limitation, the data for period 1973 to 1988 were used for calibration and 1989 to 2000 were used for validation of the model at the five catchment outlets. The 1985 land use map was used for calibration period and 2000 land use map was used for validation period. Period 19701972 and period 1987-1988 were used as "warm-up" periods for calibration and validation. The warm-up period allows the model to get the hydrological cycle fully operational.

The performance of the model for simulating discharge can be quantified by the coefficient of determination $\left(R^{2}\right)$, Nash-Sutcliffe efficiency $\left(E_{\mathrm{NS}}\right)[22]$, and relative error (RE) between the observations and the final best simulation, which were defined as follows:

$$
\begin{gathered}
R^{2}=\frac{\left[\sum_{i=1}^{n}\left(Q_{\text {sim }_{i}}-\overline{Q_{\text {sim }}}\right)\left(Q_{\mathrm{obs}_{i}}-\overline{Q_{\mathrm{obs}}}\right)\right]^{2}}{\sum_{i=1}^{n}\left(Q_{\mathrm{obs}_{i}}-\overline{Q_{\mathrm{obs}}}\right)^{2} \sum_{i=1}^{n}\left(Q_{\text {sim }_{i}}-\overline{Q_{\text {sim }}}\right)^{2}}, \\
E_{\mathrm{NS}}=1-\frac{\sum_{i=1}^{n}\left(Q_{\text {sim }_{i}}-Q_{\mathrm{obs}_{i}}\right)^{2}}{\sum_{i=1}^{n}\left(Q_{\mathrm{obs}_{i}}-\overline{Q_{\mathrm{obs}}}\right)^{2}}, \\
\mathrm{RE}=\left(\frac{\overline{Q_{\text {sim }}}-\overline{Q_{\mathrm{obs}}}}{\overline{Q_{\mathrm{obs}}}}\right) \times 100,
\end{gathered}
$$

where $n$ is the number of discharge values, $Q_{\text {sim }_{i}}$ and $Q_{\mathrm{obs}_{i}}$ are the simulated and measured values of discharge, respectively, and $\overline{Q_{\text {sim }}}$ and $\overline{Q_{\text {obs }}}$ are average of simulated and observed discharge over the simulation period, respectively.

The coefficient of determination $\left(R^{2}\right)$ is the percent of the variation that can be explained by the regression equation, and the value of $R^{2}$ can range from 0 to 1 , with higher value indicating a better model performance. The value of $E_{\mathrm{NS}}$ can range from $-\infty$ to 1 , with higher values indicating a better overall fit and 1 indicating a perfect fit. A general acceptable criteria for $E_{\mathrm{NS}}$ is set to be greater than 0.5 for monthly data. $\mathrm{RE}$ of less than or equal to $15 \%$ is considered satisfactory during model calibration and validation [23].

2.3. The Modified Palmer Drought Severity Index. Palmer drought severity index (PDSI) was developed by W. C. Palmer in 1965, which incorporated antecedent precipitation, moisture supply, and moisture demand into a hydrologic accounting system [13]. The index that intended to be of reasonable comparable local significance both in space and time has been extensively used as a measure of drought for 
both agricultural and water resources management. Basic concepts and steps for the computation of PDSI are as follows.

2.3.1. Moisture Anomaly Index. The PDSI is based on the water balance equation, and the difference $d_{i}$ between the actual precipitation $P_{i}$ and CAFEC (Climatically Appropriate For Existing Conditions) precipitation $\widehat{P}$ is an indicator of water deficiency or surplus in month $i$, which is defined as

$$
\begin{gathered}
d_{i}=P_{i}-\widehat{P}_{i} \\
\widehat{P}_{i}=\alpha \mathrm{PE}_{i}+\beta \mathrm{PR}_{i}+\gamma \mathrm{PRO}_{i}+\delta \mathrm{PL}_{i},
\end{gathered}
$$

$\mathrm{PE}_{i}$ is potential evapotranspiration; $\mathrm{PR}_{i}$ is potential recharge that indicates the amount of moisture required to bring the soil to its water holding capacity; $\mathrm{PRO}_{i}$ is potential runoff, which is defined as the difference between potential precipitation and potential recharge; and $\mathrm{PL}_{i}$ is potential loss defined as the amount of moisture that could be lost from the soil by evapotranspiration during a zero precipitation period [4]. The climatic coefficients $\alpha, \beta, \gamma, \delta$ are means for each month averaged over the base period. For example,

$$
\alpha=\frac{\overline{\mathrm{ET}}}{\overline{\mathrm{PE}}},
$$

where ET is the actual evapotranspiration and the overbar denotes the long term monthly from 1973 to 2010 in the study. In a similar way, $\beta$ is the ratio of mean actual recharge $R$ divided by mean potential recharge PR. $\gamma$ is the ratio of mean actual runoff RO divided by mean potential runoff $\mathrm{PRO}$, and $\delta$ is the ratio of mean actual loss $L$ divided by mean potential loss PL.

A two-layer bucket-type model was applied to carry out the previous hydrological accounting in the traditional PDSI computation method. However, the two-layer bucket-type model just does not consider the impacts of the spatial heterogeneity of soil, vegetation, and topographical factors on the hydrological processes in a watershed. In the study, four subbasins that correspond to meteorological stations located within the study area were selected for initially establishing Palmer drought model, and the monthly PE, ET, and RO of selected subbasins were taken directly from simulated results of calibrated SWAT model, and the other parameters can be computed based on the simulated results of soil moisture for each month $i$, which were defined as follows [24]:

$$
\begin{gathered}
R_{i}=\max \left(0,\left(\mathrm{SW}_{i}-\mathrm{SW}_{i-1}\right)\right), \\
\mathrm{PR}_{i}=\mathrm{AWC}-\mathrm{SW}_{i-1}, \\
\mathrm{PRO}_{i}=\mathrm{AWC}-\mathrm{PR}_{i}=\mathrm{SW}_{i-1}, \\
L_{i}=\max \left(0,\left(\mathrm{SW}_{i-1}-\mathrm{SW}_{i}\right)\right), \\
\mathrm{PL}_{i}=\min \left(\mathrm{PE}_{i}, \mathrm{SW}_{i-1}\right),
\end{gathered}
$$

where $\mathrm{SW}_{i-1}$ is the total soil moisture at the beginning of month and the $\mathrm{SW}_{i}$ is the total soil moisture at the ending of month. AWC is available moisture capacity. According to the Harmonized World Soil Database (HWSD), the study sets the AWC to $150 \mathrm{~mm}$.

On that basis, the difference $d_{i}$ was converted into indices of moisture anomaly $z_{i}$, which was defined as

$$
z_{i}=\kappa^{*} \times d_{i}
$$

where $\kappa^{*}$ is the climatic characteristic that can be estimated as

$$
\kappa^{*}=\frac{(\overline{\mathrm{PE}}+\bar{R})}{(\bar{P}+\bar{L})} .
$$

2.3.2. Drought Severity. The $z$-index time series were analyzed to develop criteria for the beginning and ending of drought periods and an empirical formula for determining drought severity. The index was given by the equation

$$
X_{i}=0.89 X_{i-1}+\frac{z_{i}}{55.71},
$$

where $X_{i}$ is the PDSI for the $i$ th month and $X_{i-1}$ is previous month's PDSI. The equation indicates that PDSI of a given month strongly depends on its value in the previous months and on the moisture anomaly of the actual month.

The previous equation is one of the fundamental formulas for calculating drought indices, and its establishment was just based on four subbasins. However, when the method was subsequently applied to other regions of the study area with rather different types of climate, some of the results might be peculiar and unrealistic. Therefore, in order to make the established drought mode (7) that has good spatial comparability, there is a need to adjust the monthly $k^{*}$ values and $z$,

$$
\begin{gathered}
z_{i}=K \times d_{i}, \\
K=\frac{438.91}{\sum_{1}^{12} D K^{\prime}} K^{\prime}, \\
K^{\prime}=1.2459 \lg \left[\frac{(\overline{\mathrm{PE}}+\bar{R}+\overline{\mathrm{RO}}) /(\bar{P}+\bar{L})}{\bar{D}}\right]+3.3684 .
\end{gathered}
$$

$\bar{D}$ is the mean of the absolute values of $d$.

Equations (7) and (8) were final expression of modified PDSI in Luanhe river basin based on the SWAT model and the original Palmer drought severity index.

\section{Results and Discussion}

3.1. Verification of SWAT Model. The calibration and validation were completed using the monthly discharge records at multisites from 1973 through 2000, and the results were presented in Table 2 . The values of $R^{2}$ and $E_{\mathrm{NS}}$ were greater than 0.8 for the calibration period except the upper Luanhe river at the Sandaohezi station, which indicated close relationship between simulated monthly discharges with observed values. The model slightly overestimated the monthly discharge at the Sandaohezi and Luanxian station located in the main 
TABLE 2: Evaluation of the simulation results of monthly discharge.

\begin{tabular}{|c|c|c|c|c|c|c|}
\hline & \multicolumn{3}{|c|}{ Calibration (1973-1988) } & \multicolumn{3}{|c|}{ Validation (1989-2000) } \\
\hline & $R^{2}$ & $E_{\mathrm{NS}}$ & $\mathrm{RE}$ & $R^{2}$ & $E_{\mathrm{NS}}$ & $\mathrm{RE}$ \\
\hline Hanjiaying & 0.89 & 0.89 & $-3.30 \%$ & 0.73 & 0.66 & $-1.09 \%$ \\
\hline Chengde & 0.86 & 0.85 & $-1.34 \%$ & 0.71 & 0.71 & $-7.32 \%$ \\
\hline Xiabancheng & 0.87 & 0.87 & $-5.82 \%$ & 0.68 & 0.62 & $-2.75 \%$ \\
\hline Sandaohezi & 0.78 & 0.72 & $1.05 \%$ & 0.71 & 0.62 & $-12.01 \%$ \\
\hline Luanxian & 0.93 & 0.93 & $3.40 \%$ & 0.92 & 0.91 & $-2.59 \%$ \\
\hline
\end{tabular}

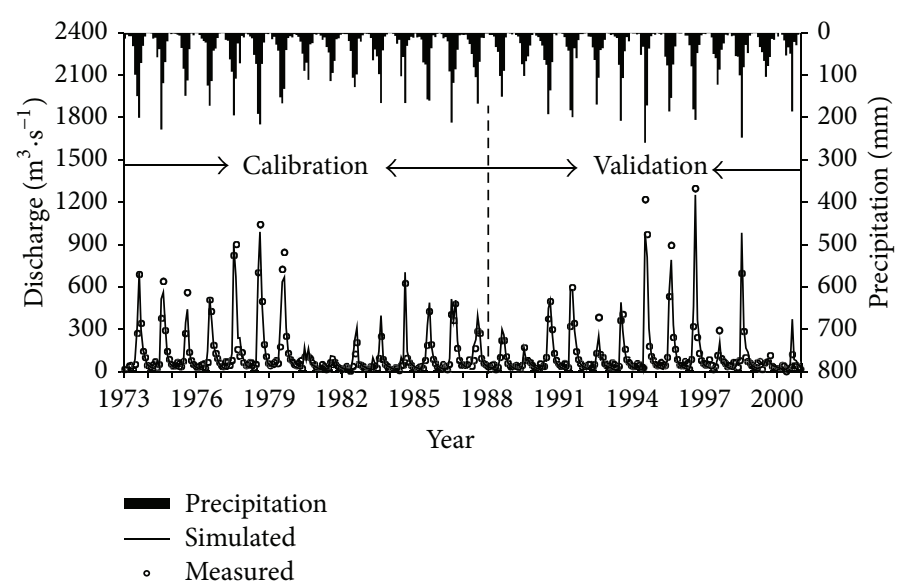

FIGURE 2: Comparison of the simulation and measured monthly hydrograph at Luanxian.

stream and underestimated the monthly discharge at other hydrological stations of three main tributaries, but the relative errors were less than $5 \%$.

Because there were no precipitation records of gauging stations after 1988, the study used the interpolated data based on precipitation records of meteorological stations from 1989 to 2010. Therefore, the spatial heterogeneity of precipitation cannot be well reflected in some years, which led to the monthly discharges being underestimated at each hydrological station, and the value of $R^{2}$ and $E_{\mathrm{NS}}$ had decreased for validation period. Even so, the indicators basically can meet the requirements of accuracy. These results showed that the calibrated model can describe the hydrological processes, implying that SWAT model was applicable to the Luanhe river basin. The result after calibration and validation at Luanxian station was shown in Figure 2.

\subsection{The Verification of Modified Palmer Drought Severity} Index. On the basis of the previous drought model, the values of monthly PDSI for each subbasin were calculated from 1973 to 2010 . In order to verify the rationality of the model, the documented real drought [25] and drought area based on modified PDSI in the study were compared (Figure 3 ).

According to the documented records, during the period of 1973-1990, typical severe and extreme drought occurred in 1975, 1980-1984, and 1989. From Figure 3, it can be seen that the average monthly drought area of documented drought years based on modified PDSI was significantly larger than other years, especially drought area made up $69.06 \%$ of the

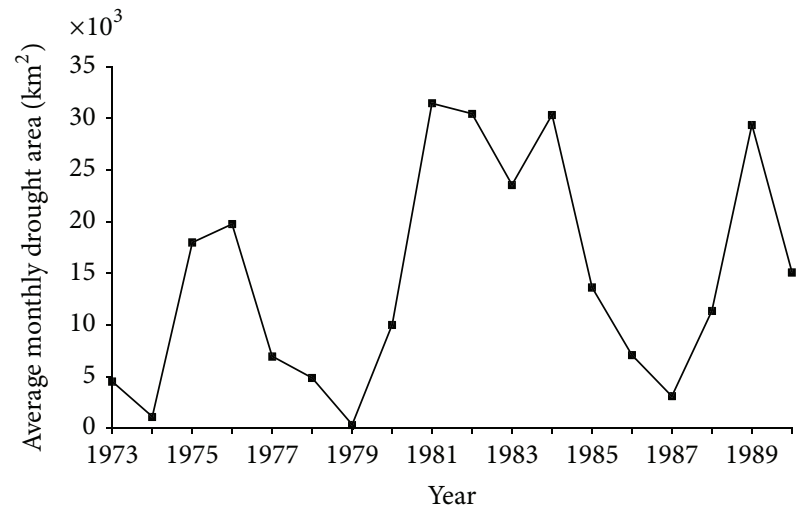

FIGURE 3: Average monthly drought area from 1973 to 1990 in Luanhe river basin.

basin in 1981, which was consistent with the documented drought. The value of drought indices based on the SWAT hydrological model and Palmer drought severity index can better describe the characteristics of regional drought evolution in the Luanhe river basin.

The drought evaluation results based on modified PDSI indicated that drought occurred in 1976, but there were no historical records. The reason of the disagreement was that historical records focus on the drought disaster, but the drought indices were mainly intended to evaluate drought from a water balance viewpoint [26]. Thus, there exist many other factors affecting the change from drought to disaster, 

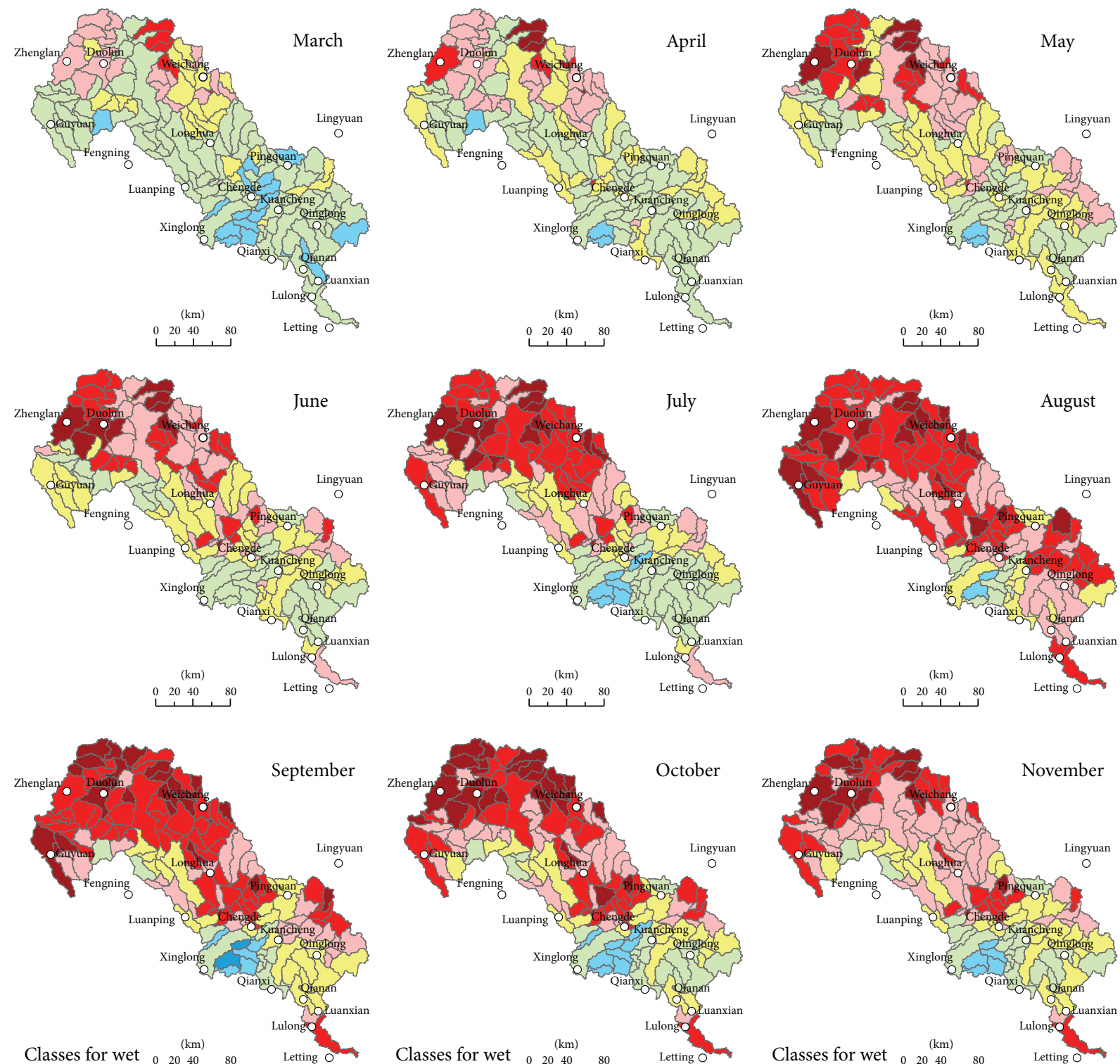
and dry periods $\stackrel{0}{2} \stackrel{20}{40} \stackrel{40}{\perp}$

and dry periods $\begin{array}{llll}0 & 20 & 40 & 80\end{array}$

Extremely drought

- Extremely drought

Extremely drought

- Severely drought

- Severely drought

$\square$ Moderately drought

- Severely drought

$\square$ Moderately drought

$\square$ Slightly drought

$\square$ Slightly drought

$\square$ Normal

$\square$ Slightly wet

$\square$ Slightly wet

$\square$ Moderately wet

$\square$ Slightly drought

$\square$ Normal

$\square$ Slightly wet

- Moderately wet

FIgURE 4: The distributed map of drought grades in 1989 based on modified PDSI.

that is, irrigation, which may lead to the little differences between documented and evaluated drought.

The drought distribution using modified PDSI was further verified in 1989 (Figure 4). It can be seen that the signs of drought came into being with the arrival of March, and it was distributed mainly in the northern Weichang county in the upper reach of Luanhe river basin. But after that, the drought area has gradually extended and the drought lasted until November. Overall, the spatial distribution of drought evaluation was consistent with documented real drought.

\subsection{Spatial-Temporal Characteristics of Drought in Luanhe River Basin}

3.3.1. Spatial Distribution Characteristics of Drought. Drought frequency representing how often drought occurs was calculated through dividing the number of months at which drought occurs by total months. The distribution map of drought frequency in Luanhe river basin was represented in Figure 5, which showed a high degree of spatial heterogeneity on subbasin level. High drought frequency areas 


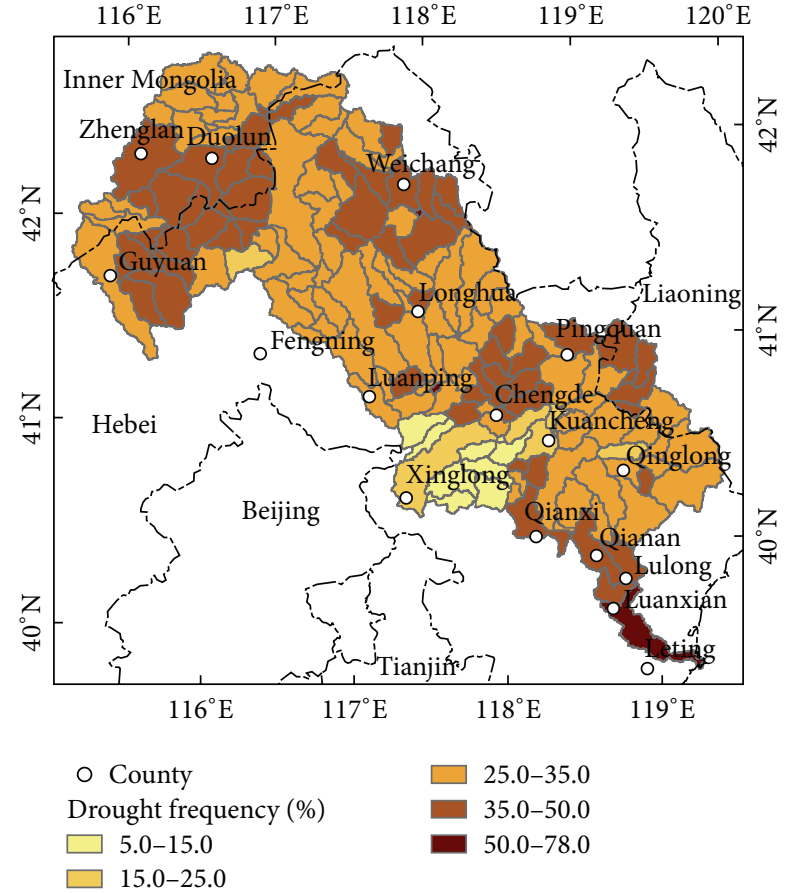

FIGURE 5: Distribution map of drought frequency based on modified PDSI.

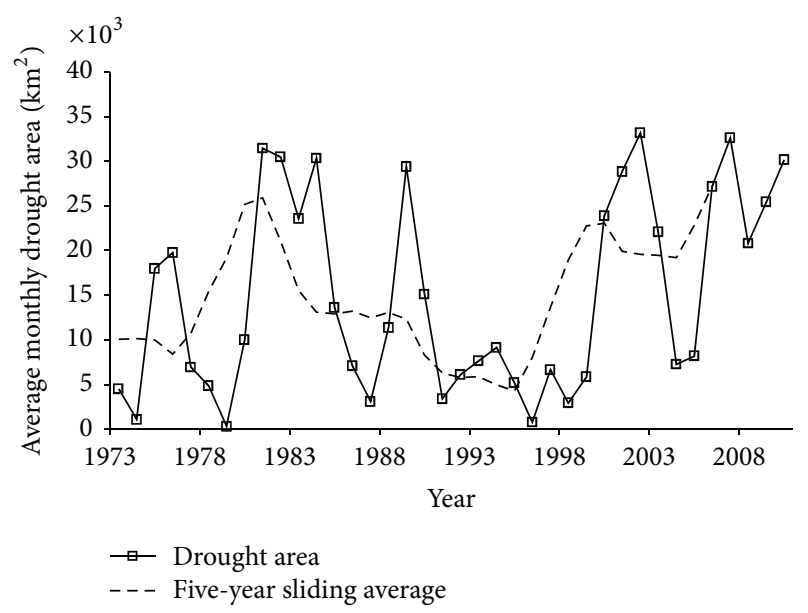

FIgURE 6: Annual variation of average monthly drought area from 1973 to 2010 .

were mainly distributed in the grassland regions of upstream located in the eastern part of Inner Mongolia plateau, including Duolun and Guyuan county, the northern Weichang, Chengde and Pingquan county of middle reaches, and Qianxi, Qianan and Lulong county of downstream. The drought frequency was higher than $35 \%$ in these areas. And in relative terms, the drought less occurs in the area of southern Luanping to Xinglong county, where drought frequency was less than $20 \%$.

Due to the limitation of data, the irrigation is not considered in the established SWAT model in the south of Luanxian county, downstream of Luanhe river, and the monthly natural streamflow; namely adding the social and economic water used including the water storage of the reservoirs, industrial and agricultural water used to measure runoff was used for model calibration and validation, which can eliminate the impact of human activities. Therefore, the evaluation results of drought frequency based on modified PDSI showed that these regions had the highest frequency. However, in practice, there are many large-scale irrigation areas in these regions where the frequency of drought that actually happened was not high. Thus, the evaluation results had not considered the effect of human activity on drought, that there was a need to further improve the established drought model.

3.3.2. Temporal Variation of Drought. The temporal variation of drought was analyzed with average monthly drought area from 1973 to 2010 (Figure 6), which showed that the drought had obviously interannual and interdecadal fluctuation in Luanhe river basin, and the average drought area was $14954.69 \mathrm{~km}^{2}$. From 1970s to the late 1980s, the drought exhibited a significant upward trend. Compared with 1973 to 1990, the drought degree of 1990 to 2000 decreased. But the drought area increased rapidly again after 2000. Overall, the drought had a significant upward trend.

The break point of drought area was detected in 1985 and 2006 with Mann-Kendall's test. Because of increased precipitation, the drought showed an alleviating trend from 1985 to 2005 in the Luanhe river basin. However, with the decreasing of precipitation and the effect of human activities, the drought had intensified after 2006.

\section{Conclusions}

The SWAT model was applied to modify the Palmer drought severity index (PDSI) in Luanhe river basin. Calibration results of the SWAT model show that the good agreement between the measured and simulated monthly discharges. But due to the interpolation quality of precipitation data, the monthly discharges were underestimated and the value of $R^{2}$ and $E_{\mathrm{NS}}$ had decreased for validation period. Even so, the indicators basically can also meet the requirements of accuracy. It showed the calibrated model can be used to describe the hydrological processes in the study area. Then the simulation results of hydrological components were used for the calculation procedure of the PDSI on subbasin level. The method was applied to drought evaluation in Luanhe river basin, North China, and good results were obtained.

Many studies have analyzed drought trend with PDSI. Dai [6] compared and evaluated four forms of PDSI using available climate data from 1850 to 2008. Zhai et al. [27] analyzed the time series of the average annual PDSI and SPI calculated for 483 meteorological stations for 10 large regions covering the territory of China. Compared with the previous researches, the modified PDSI based on SWAT model not only can describe the spatial difference of regional drought, but also could improve the physical mechanism of PDSI and extend the scale from point to subbasin because the twosoil layer for calculating water balance was replaced by the distributed hydrological model. 
The work should be considered as an attempt to monitor drought that integrated the Palmer drought severity index and SWAT model. However, there exist some limitations in the study. Due to insufficient irrigational data availability, the model could not represent the effect of human activity on drought. Besides, it is difficult to acquire the measure value of some internal state variables, so the model calibration was based on a comparison between simulated and measured discharges. In the next phase of this research, it is of major importance to take into account irrigation, and multivariable calibration and validation approach should be used to produce more realistic input parameters for the SWAT model and improve the evaluation accuracy of drought.

\section{Acknowledgments}

The paper was supported by the National Basic Research Program of China (no. 2010CB951102), the National Key Technology R\&D Program of China during the 12th Fiveyear Plan Period (no. 2012BAC19B03), and the Foundation for Innovative Research Groups of the National Natural Science Foundation of China (no. 51021066).

\section{References}

[1] T. Sternberg, "Regional drought has a global impact," Nature, vol. 472, no. 7342, p. 169, 2011.

[2] L. Vasiliades and A. Loukas, "Hydrological response to meteorological drought using the Palmer drought indices in Thessaly, Greece," Desalination, vol. 237, no. 1-3, pp. 3-21, 2009.

[3] S. M. Quiring and T. N. Papakryiakou, "An evaluation of agricultural drought indices for the Canadian prairies," Agricultural and Forest Meteorology, vol. 118, no. 1-2, pp. 49-62, 2003.

[4] I. J. Szép, J. Mika, and Z. Dunkel, "Palmer drought severity index as soil moisture indicator: physical interpretation, statistical behaviour and relation to global climate," Physics and Chemistry of the Earth, vol. 30, no. 1-3, pp. 231-243, 2005.

[5] L. Vasiliades, A. Loukas, and N. Liberis, "A water balance derived drought index for Pinios river basin, Greece," Water Resources Management, vol. 25, no. 4, pp. 1087-1101, 2011.

[6] A. Dai, "Characteristics and trends in various forms of the Palmer Drought Severity Index during 1900-2008," Journal of Geophysical Research D, vol. 116, no. 12, Article ID D12115, 2011.

[7] T. Gebrehiwot, A. van der Veen, and B. Maathuis, "Spatial and temporal assessment of drought in the Northern highlands of Ethiopia," International Journal of Applied Earth Observation and Geoinformation, vol. 13, no. 3, pp. 309-321, 2011.

[8] A. K. Mishra and V. P. Singh, "A review of drought concepts," Journal of Hydrology, vol. 391, no. 1-2, pp. 202-216, 2010.

[9] R. R. Heim Jr., "A review of twentieth-century drought indices used in the United States," Bulletin of the American Meteorological Society, vol. 83, no. 8, pp. 1149-1165, 2002.

[10] W. M. Alley, “The Palmer Drought Severity Index: limitations and assumptions," Journal of Climate \& Applied Meteorology, vol. 23, no. 7, pp. 1100-1109, 1984.

[11] Q. S. Hu and G. D. Willson, "Effects of temperature anomalies on the Palmer drought severity index in the central United States," International Journal of Climatology, vol. 20, pp. 189911911, 2000.
[12] E. Liang, X. Shao, H. Liu, and D. Eckstein, "Tree-ring based PDSI reconstruction since AD 1842 in the Ortindag Sand Land, east Inner Mongolia," Chinese Science Bulletin, vol. 52, no. 19, pp. 2715-2721, 2007.

[13] W. C. Palmer, "Meteorological drought," Research Paper 45, US Weather Bureau, Washington, DC, USA, 1965.

[14] J. Sheffield, E. F. Wood, and M. L. Roderick, "Little change in global drought over the past 60 years," Nature, vol. 491, no. 7424, pp. 435-438, 2012.

[15] Z. X. Xu, J. P. Pang, C. M. Liu, and J. Y. Li, "Assessment of runoff and sediment yield in the miyun reservoir catchment by using SWAT model," Hydrological Processes, vol. 23, no. 25, pp. 36193630, 2009.

[16] J. G. Arnold, R. Srinivasan, R. S. Muttiah, and J. R. Williams, "Large area hydrologic modeling and assessment-part I: model development," Journal of the American Water Resources Association, vol. 34, no. 1, pp. 73-89, 1998.

[17] S. Wang, S. Kang, L. Zhang, and F. Li, "Modelling hydrological response to different land-use and climate change scenarios in the Zamu River basin of northwest China," Hydrological Processes, vol. 22, no. 14, pp. 2502-2510, 2008.

[18] K. M. Loague and R. A. Freeze, "A comparison of rainfallrunoff modeling techniques on small upland catchments," Water Resources Research, vol. 21, no. 2, pp. 229-248, 1985.

[19] S. L. Neitsch, J. G. Arnold, J. R. Kiniry, and J. R. Williams, Soil and Water Assessment Tool, Theoretical Documentation (Version 2005), Grassland, Soil and Water Research Laboratory, Agricultural Research Service \& Blackland Research Center, Texas Agricultural Experiment Station, Temple, Tex, USA, 2005.

[20] K. E. Saxton, W. J. Rawls, J. S. Romberger, and R. I. Papendick, "Estimating generalized soil-water characteristics from texture," Soil Science Society of America Journal, vol. 50, no. 4, pp. 10311036, 1986.

[21] C. L. Tong, W. J. Zhang, and Y. Tang, "Estimation of daily solar radiation in China," Chinese Journal of Agrometeorology, vol. 26, no. 3, pp. 165-169, 2005 (Chinese).

[22] J. E. Nash and J. V. Sutcliffe, "River flow forecasting through conceptual models-part I: a discussion of principles," Journal of Hydrology, vol. 10, no. 3, pp. 282-290, 1970.

[23] S. Kumar and V. Merwade, "Impact of watershed subdivision and soil data resolution on swat model calibration and parameter uncertainty," Journal of the American Water Resources Association, vol. 45, no. 5, pp. 1179-1196, 2009.

[24] J.-J. Xu and D.-W. Yang, "New model for drought estimation and prediction based on distributed hydrological simulation," Journal of Hydraulic Engineering, vol. 41, no. 6, pp. 739-747, 2010 (Chinese).

[25] Water Resources Department of Hebei Province, Floods and Droughts of Hebei Province, China Water \& Power Press, Beijing, China, 1997.

[26] N. B. Guttman, "Comparing the palmer drought index and the standardized precipitation index," Journal of the American Water Resources Association, vol. 34, no. 1, pp. 113-121, 1998.

[27] J. Zhai, B. Su, V. Krysanova, T. Vetter, C. Gao, and T. Jiang, "Spatial variation and trends in PDSI and SPI indices and their relation to streamflow in 10 large regions of china," Journal of Climate, vol. 23, no. 3, pp. 649-663, 2010. 


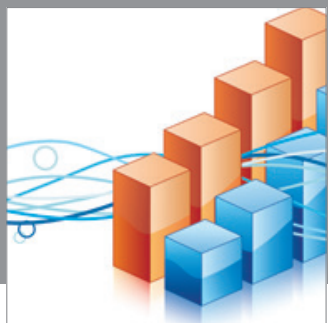

Advances in

Operations Research

mansans

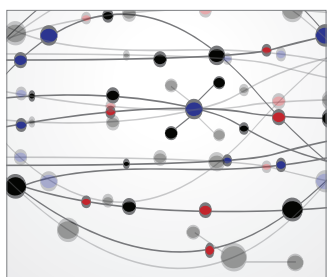

The Scientific World Journal
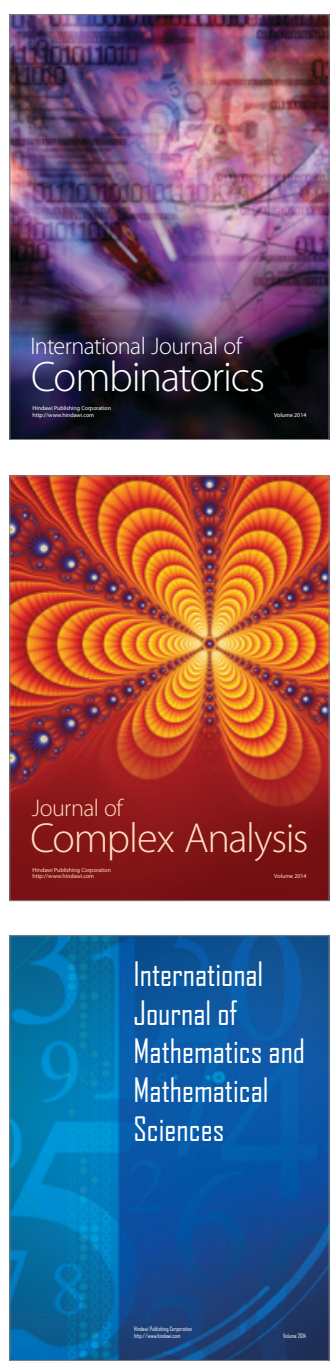
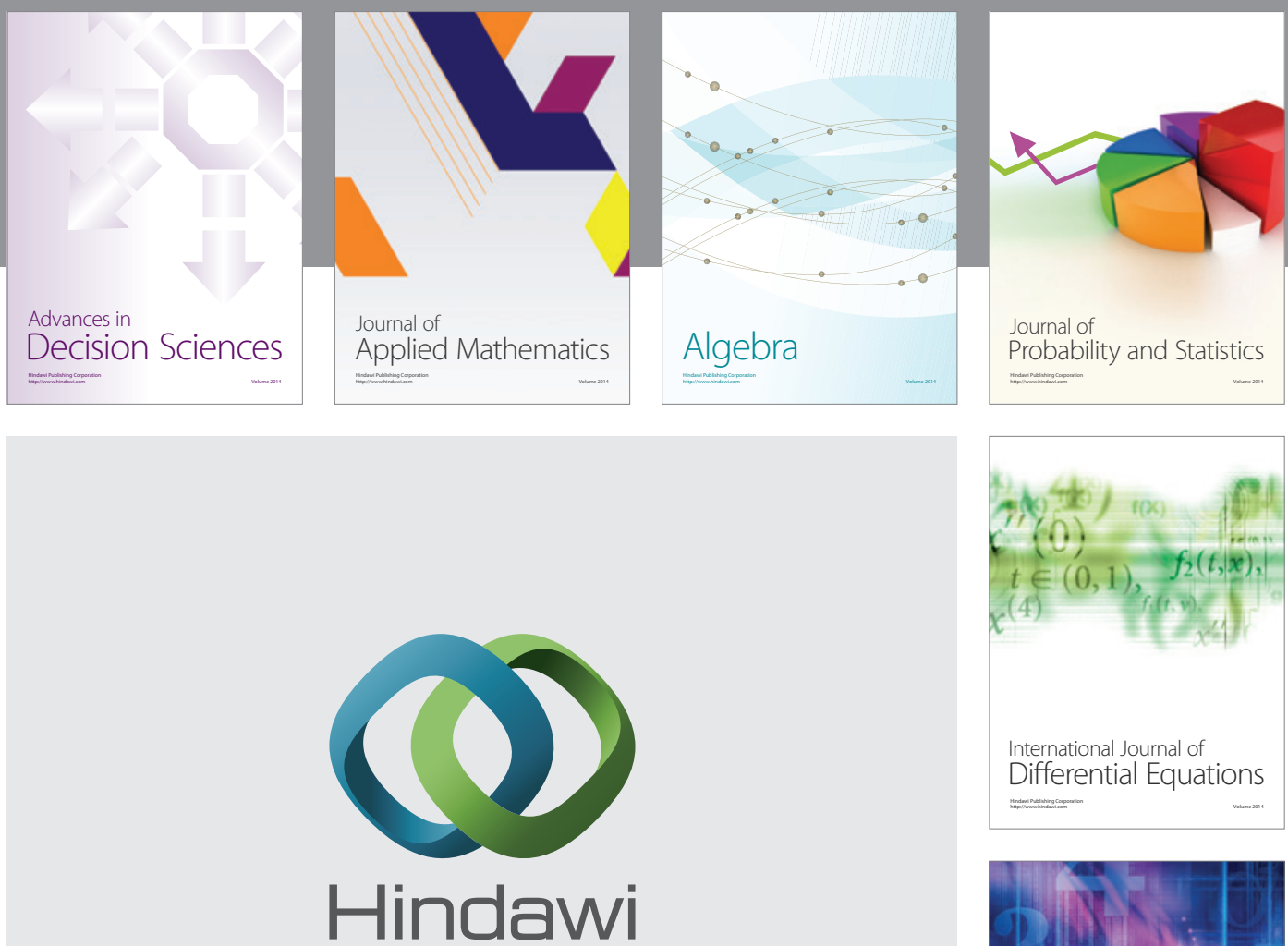

Submit your manuscripts at http://www.hindawi.com
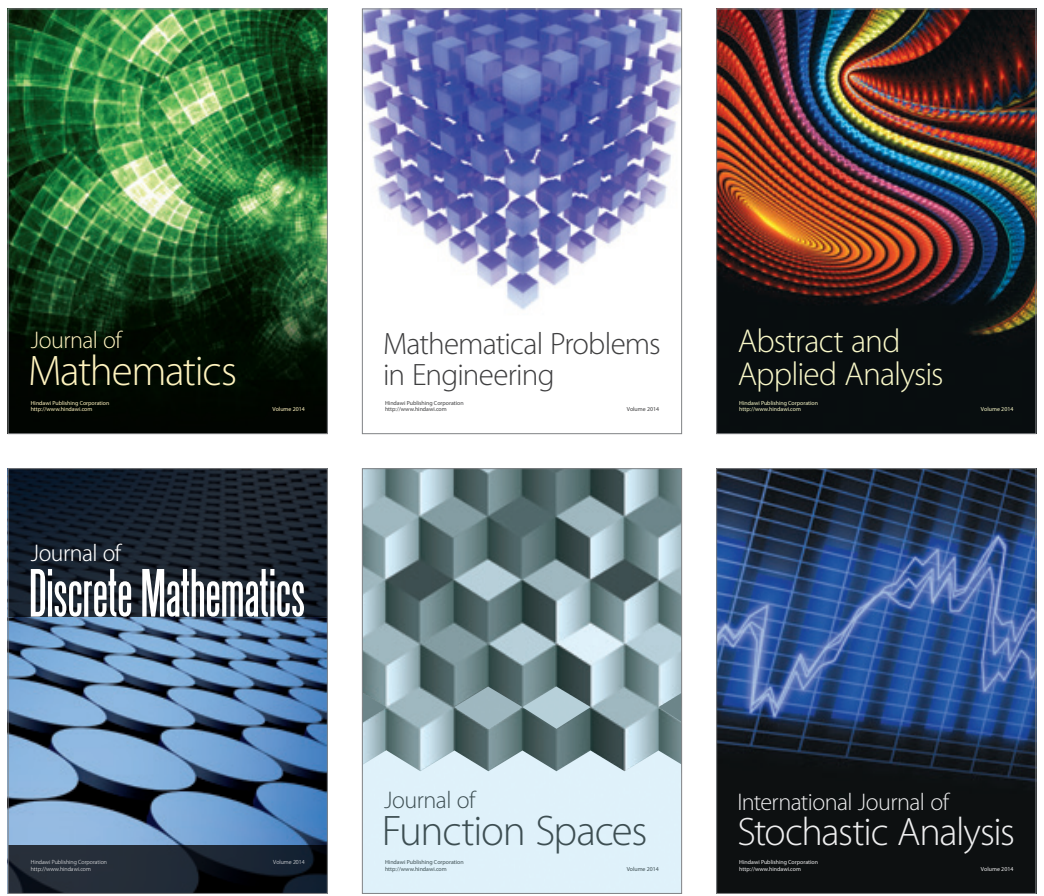

Journal of

Function Spaces

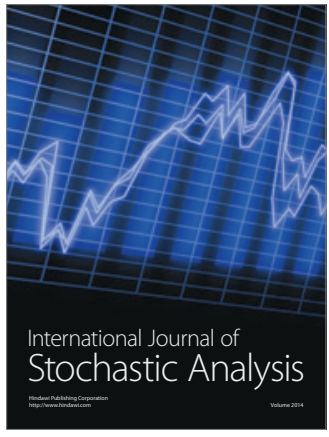

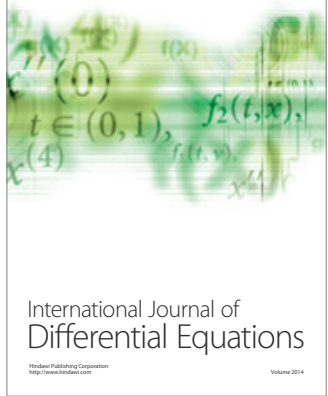
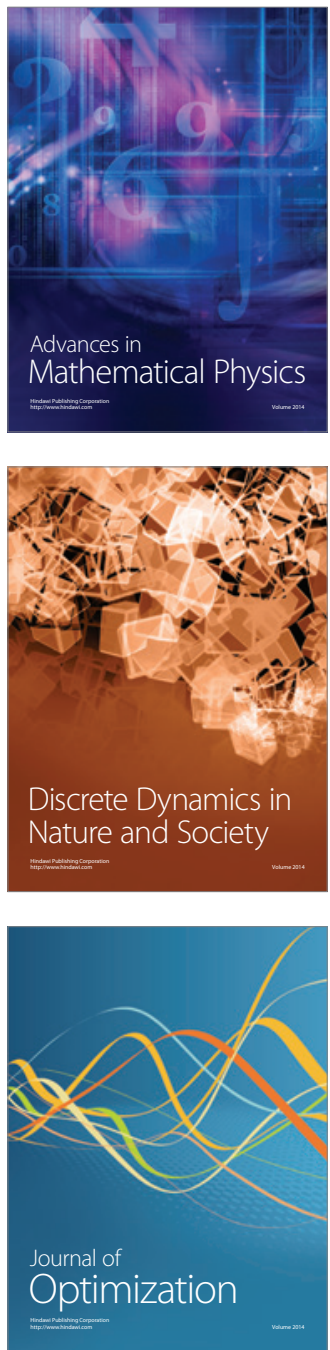